\title{
Role Model: Lesley Rees
}

The patient perspective should be at the heart of everything a doctor does, the consultant and professor of paediatric nephrology tells Adrian O'Dowd

\section{Adrian O'Dowd}

London, UK

It was during her first year at grammar school that Lesley Rees began to consider a career in medicine. "My mother developed Parkinson's disease in her early 40s," she says. "I read all I could about it and became interested in becoming a doctor."

It was, however, seeing her mother paraded in front of medical students who were encouraged to shout out diagnoses that made her determined to change how the profession treated patients.

"I was outraged and became determined to become a doctor and change the way doctors spoke to patients," she says.

Rees attended the University of Manchester medical school in the 1970 s, at a time when only $11 \%$ of the students were female. "That was the highest proportion in the country," she says. "I'm pleased that this has now changed."

It was while at medical school that Rees decided that she wanted to be a paediatrician. "It was the opportunity to influence the health of a human being at the earliest opportunity," she says.

Between 1984 and 1990, Rees was a lecturer in paediatrics at Guys Hospital in London, in what was the first job share of its kind. Since then, she has been a consultant at Great Ormond Street Hospital.

Over her career, Rees has managed to secure more than $£ 2 \mathrm{~m}$ $(€ 2.3 \mathrm{~m} ; \$ 2.6 \mathrm{~m})$ in research grant funding and has published over 150 peer reviewed articles and reviews. Her Handbook of Paediatric Nephrology is used by trainees and consultants worldwide. She has also influenced national policy through her work with the Department of Health, specialty groups, the royal colleges, and NICE.

In 2016 she was awarded the lifelong achievement award by the International Paediatric Nephrology Association for services to children with kidney disease and her role as co-editor of the journal Paediatric Nephrology.

"Frontline working with families will always be what I most enjoy. But I also enjoy research because the whole point of it is to improve the quality of life of our patients," she says.
"The feedback I get from patients when they've left my care and have gone on to adult care is very rewarding. They come back and let me know how their life is progressing. I often get emails telling me about weddings and babies."

Rees has learned a lot from frontline care. "You have to be absolutely obsessional in the care of your patients, looking at every single aspect in a holistic sense," she says.

"You look at their blood results but you are also looking at their quality of life, their nutrition, their psychosocial support, their schooling, the impact of their illness on their family. The whole patient is very important."

Rees' advice for young doctors underlines her passion for keeping the patient at the centre of all she does. "Always try to think how your patients and their families must be feeling and be sensitive to their needs. Also, keep time for your partner and family."

\section{Nominated by Stephen Marks.}

"Professor Rees is an excellent clinician and diagnostician with an outstanding academic record. She is a leader in local, national, and international research.

"Despite her young age and health scares, she continues to work at full pace and is the most efficient of doctors with excellent time management skills. "She will leave a legacy of a generation of paediatric nephrologists who are grateful for having learnt their trade from her."

Stephen Marks is a consultant paediatric nephrologist, Great Ormond Street Hospital.

Nominate a role model: To nominate someone who has been a role model during your medical career, send their name, job title, and the reason for your nomination to arimmer@bmj.com

Published by the BMJ Publishing Group Limited. For permission to use (where not already granted under a licence) please go to http://group.bmj.com/group/rights-licensing/ permissions 